\title{
Size-Controlled $\mathrm{Cu}_{2} \mathrm{O}$ Nanocubes by Pulse Electrodeposition
}

\author{
You-Jung Song, Sang-Beom Han, Hyun-Hwi Lee ${ }^{\dagger}$, and Kyung-Won Park* \\ Department of Chemical and Environmental Engineering, Soongsil University, Seoul 156-743, Republic of Korea \\ †Pohang Accelerator Laboratory, San-31 Hyoja-dong, Pohang, Kyungbuk, 790-784, Republic of Korea
}

(Received January 20, 2010 : Accepted February 8, 2010)

\begin{abstract}
In this work, highly uniform size-controlled $\mathrm{Cu}_{2} \mathrm{O}$ nanocubes can be successfully formed by means of pulse electrodeposition. The size distribution, crystal structure, and chemical state of deposited $\mathrm{Cu}_{2} \mathrm{O}$ nanocubes are characterized using scanning electron microscopy, transmission electron microscopy, X-ray diffraction and X-ray photoelectron spectroscopy. The phase transition from $\mathrm{Cu}_{2} \mathrm{O}$ to $\mathrm{Cu}$ can be controlled by constant current electrodeposition as a function of deposition time. In particular, the size of the $\mathrm{Cu}_{2} \mathrm{O}$ nanocubes can be controlled using pulse electrodeposition as a function of applied current density.
\end{abstract}

Keywords : $\mathrm{Cu}_{2} \mathrm{O}$ Nanocube, Size control, Pulse electrodeposition, Phase transition

\section{Introduction}

Cuprous oxide $\left(\mathrm{Cu}_{2} \mathrm{O}\right)$ crystal structure has advantages of no toxicity, low cost, availability, and high absorption coefficient at $2.17 \mathrm{eV}(438 \mathrm{~nm}){ }^{1,2)}$ Such distinct properties make $\mathrm{Cu}_{2} \mathrm{O}$ potential candidates for solar energy cell, catalysis, and gas sensors. ${ }^{3-5}$ In addition, the $\mathrm{Cu}_{2} \mathrm{O}$ phase is useful for negative electrodes in lithium ion batteries and for photochemical decomposition of water into $\mathrm{O}_{2}$ and $\mathrm{H}_{2}$ under visible light irradiation. ${ }^{6-8)}$

It has been well known that the shape and size-controlling of inorganic materials has great effects on their widely varying properties. ${ }^{9}$ Many efforts have been intensively devoted to the synthesis of $\mathrm{Cu}_{2} \mathrm{O}$ with a variety of shapes using electrochemical, thermal oxidation, solutionphase synthesis, sputtering, and chemical vapour deposition. ${ }^{10-17)}$ Among them, pulse electrodeposition method was found to be useful for nanostructure fabrication because of simple operation and uniform deposition. ${ }^{18-20}$ However, since it is stable in an extremely narrow range, the $\mathrm{Cu}_{2} \mathrm{O}$ phase should be carefully fabricated.

Here, we report phase transition between $\mathrm{Cu}_{2} \mathrm{O}$ and $\mathrm{Cu}$ and size-controlling of $\mathrm{Cu}_{2} \mathrm{O}$ nanocubes using electrodeposition method. Using scanning electron microscopy (SEM), transmission electron microscopy (TEM), X-ray diffraction (XRD) and X-ray photo-

*E-mail: kwpark@ssu.ac.kr electron spectroscopy (XPS), size distribution, crystal structure, and chemical state of the electrodes were characterized.

\section{Experimental}

The $\mathrm{Cu}_{2} \mathrm{O}$ and $\mathrm{Cu}$ on indium tin oxide (ITO) glass were electrodeposited in $5 \mathrm{mM}$ copper sulfate $\left(\mathrm{CuSO}_{4}\right)$ aqueous solution. Electrodeposition was carried out under a constant mode or pulse mode, using a three-electrode cell with a Pt wire, an $\mathrm{Ag} / \mathrm{AgCl}$ electrode and ITO glass as a counter, reference and working electrode, respectively. In case of an electrodeposition by constant current mode, $-1 \mathrm{~mA} / \mathrm{cm}^{2}$ of direct current was applied for 10 , 60,300 and $600 \mathrm{~s}$, respectively. In addition, $\mathrm{Cu}_{2} \mathrm{O}$ nanocubes were prepared by pulse electrodeposition from -1 to $-4 \mathrm{~mA} / \mathrm{cm}^{2}$ of pulse current with the $0.1 \mathrm{~s}$ on-time and $0.3 \mathrm{~s}$ off-time for $10 \mathrm{~s}$ at room temperature.

The morphology of deposited films was observed by means of SEM (JEOL JSM-6360A). The SEM investigation was carried out at room temperature at a voltage of $13 \mathrm{kV}$. TEM investigation was carried out using a Phillips-F20 Electron Microscope at an accelerating voltage of $200 \mathrm{kV}$ and $\mathrm{Cu}$ grid was used as substrates. The crystal structures of the films were confirmed by XRD (Pohang Accelerator Laboratory, 5A HFMS). In order to analyze and compare the surface chemical states of the samples, XPS was carried out using a VG Scientific (ESCALAB250, Korea Basic Science 
Institute, Busan Branch) photoelectron spectrometer. The X-ray source was $\mathrm{Al} \mathrm{K}$ a with $1486.6 \mathrm{eV}$ operating at $150 \mathrm{kV}$ and $150 \mathrm{~W}$. The base pressure of the system was $2 \times 10^{-9}$ Torr.

\section{Results and discussion}

Fig. 1 shows SEM images of electrodes electrodeposited at $-1 \mathrm{~mA} / \mathrm{cm}^{2}$ for $10,60,300$, and $600 \mathrm{~s}$. At the deposition time of $10 \mathrm{~s}$, as shown in Fig. 1(a), the shape of the electrode is found to be cube. However, as shown in Fig. 1(b) and (c), as the deposition time increases, the density of cube in the electrodes is diminished and starts to agglomerate. Thus, as shown in Fig. 1(d), at the deposition time of $600 \mathrm{~s}$, the cube in the electrode completely disappears with complete agglomeration. To identify crystal structures in the electrodes, as shown in Fig. 1(e), the XRD analysis
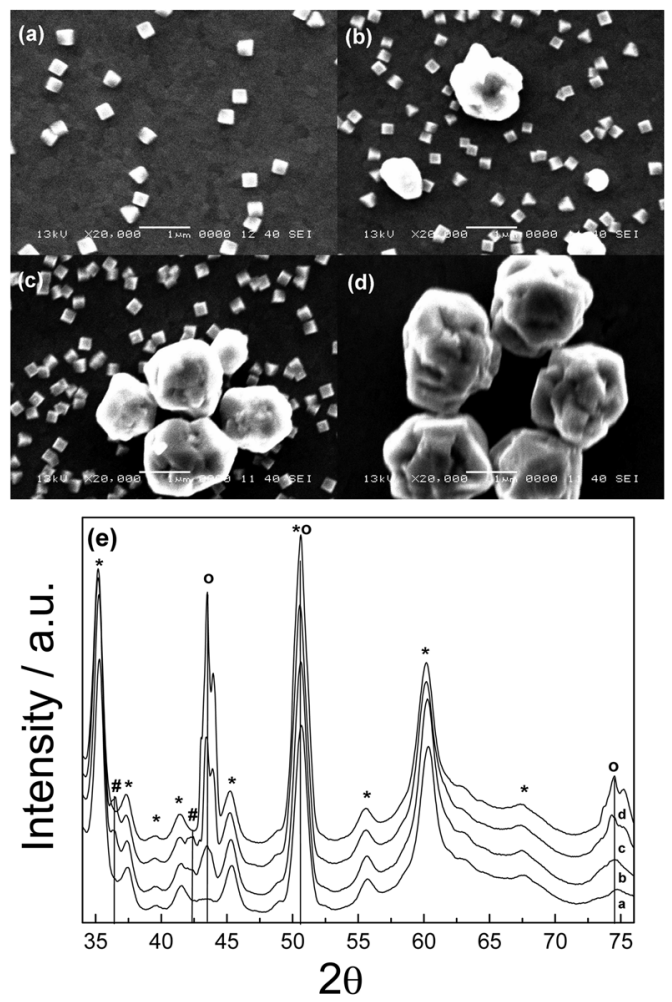

Fig. 1. SEM images of the electrodes electrodeposited for (a) 10, (b) 60, (c) 300 and (d) 600 s. (e) X-ray diffraction patterns of the electrodes electrodeposited for a.10, b.60, c.300 and d.600 s. The $\left({ }^{*}\right),(\#)$ and (o) mark in the Fig. 1(e) represent XRD patterns of ITO glass, $\mathrm{Cu}_{2} \mathrm{O}$ and $\mathrm{Cu}$, respectively. was carried out. At the deposition time of $10 \mathrm{~s}$, as indicated in Fig. 1(e)-a, the XRD peaks at 36.4 and 42.2 are assigned to (111) and (200) planes of $\mathrm{Cu}_{2} \mathrm{O}$, respectively. Accordingly, the phase electrodeposited at $-1 \mathrm{~mA} / \mathrm{cm}^{2}$ for $10 \mathrm{~s}$ is found to be $\mathrm{Cu}_{2} \mathrm{O}$ cube. However, as shown in Fig. 1(e)-b and c, as the deposition time increases from 60,300 , to $600 \mathrm{~s}$, in addition to the XRD pattern of $\mathrm{Cu}_{2} \mathrm{O}$, the diffraction peaks related to (111), (200) and (220) planes of $\mathrm{Cu}$ metal appear at 43.3, 50.4 and 74.1, respectively. This means that the peak intensity of $\mathrm{Cu}_{2} \mathrm{O}$ is still stronger and the XRD peaks of $\mathrm{Cu}$ metallic phase start to appear. As already observed in the Fig. 1(b) and (c), the cube in the electrodes started to disappear and simultaneously agglomerate. Therefore, the agglomerates in the electrodes must be the most of $\mathrm{Cu}$ metallic phase including a slight amount of $\mathrm{Cu}_{2} \mathrm{O}$. In the XRD pattern of the electrode deposited for $600 \mathrm{~s}$ with complete agglomeration of the phase, as shown in Fig. 1(e)-d, the peak of $\mathrm{Cu}_{2} \mathrm{O}$ still appears. However, that of $\mathrm{Cu}$ metallic phase becomes relatively stronger.

To confirm chemical transition between $\mathrm{Cu}^{+}$and $\mathrm{Cu}^{\circ}$ of the $\mathrm{Cu}_{2} \mathrm{O}$ and $\mathrm{Cu}$, respectively, X-ray photoelectron spectra of the electrodes were obtained as shown in Fig. 2. The peak at $932.50 \mathrm{eV}$, which was corrected with reference to $\mathrm{C} 1 \mathrm{~s}$ (284.6 eV), corresponding to the binding energy of $\mathrm{Cu} 2 \mathrm{p}$, is in good agreement with data observed in $\mathrm{Cu}_{2} \mathrm{O}{ }^{21)} \mathrm{In}$ addition, the peak at $932.70 \mathrm{eV}$ and $933.60 \mathrm{eV}$ corresponds to $\mathrm{Cu}$ and $\mathrm{O}^{2-}$-adsorbed $\mathrm{Cu}$, respectively. ${ }^{22)}$ In the spectrum of the electrode deposited for $10 \mathrm{~s}$, there is only $\mathrm{Cu}_{2} \mathrm{O}$ peak. However, as the deposition time increases from 10 to $600 \mathrm{~s}$, the portion of $\mathrm{Cu}_{2} \mathrm{O}$ is reduced while that of $\mathrm{Cu}$ is increased. The O1s core-level spectrum, peak at the lower energy of $530.3 \mathrm{eV}$, is in good agreement with $\mathrm{O}^{2-}$ in $\mathrm{Cu}_{2} \mathrm{O}$. The XPS peak at the higher energy of $531.7 \mathrm{eV}$, is attributed to $\mathrm{O}$ adsorbed on the surface. It can be seen that the portion of $\mathrm{O}^{2-}$ in $\mathrm{Cu}_{2} \mathrm{O}$ reduces with increasing deposition time. This demonstrates that $\mathrm{Cu}_{2} \mathrm{O}$ is continuously reduced to $\mathrm{Cu}$ metal. Thus, it is obvious that combining the XRD and XPS data, the electrodes deposited for 10 to $600 \mathrm{~s}$ shows phase transition between $\mathrm{Cu}_{2} \mathrm{O}$ and $\mathrm{Cu}$.

During electrodeposition process under any given condition, cupper ions are continuously reduced. In other words, $\mathrm{Cu}_{2} \mathrm{O}$ is formed and then perfectly reduced to $\mathrm{Cu}$ metallic phase as the following equations:

$$
\mathrm{Cu}^{2+}+\mathrm{e} \rightarrow \mathrm{Cu}^{+}
$$



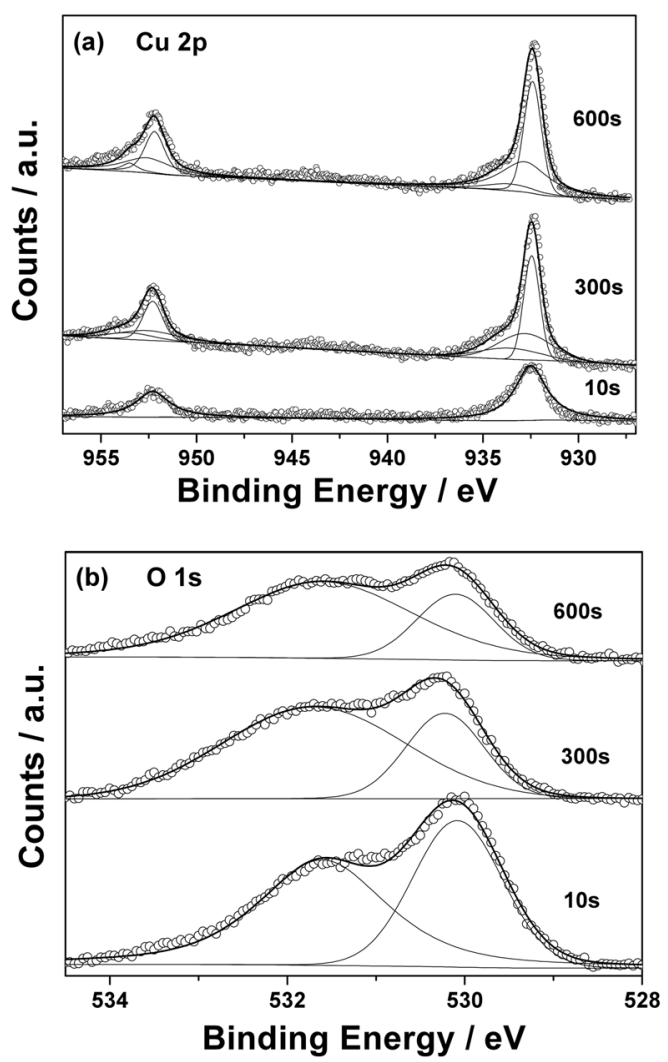

Fig. 2. XPS spectra of (a) Cu2p and (b) O1s in the electrodes. The 10, 300 and $600 \mathrm{~s}$ represent electrodeposition time.

$$
\begin{aligned}
& 2 \mathrm{Cu}^{+} \rightarrow \mathrm{Cu}^{0}+\mathrm{Cu}^{2+} \\
& \mathrm{Cu}^{+}+\mathrm{e} \rightarrow \mathrm{Cu}^{0}
\end{aligned}
$$

Fig. 3 shows SEM images of the electrodes fabricated by pulse electrodeposition with current densities of $-1,-2,-3$, and $-4 \mathrm{~mA} / \mathrm{cm}^{2}$. In the present study, on-time and total deposition time is $0.1 \mathrm{~s}$ and $10 \mathrm{~s}$, respectively. As shown in the Fig. 3, the electrodes formed by pulse current mode consist of more than $70 \%$ of cubes and the rest of other shapes. ${ }^{18-20)}$ However, in our study, as applied current density is increased, an average size of cubes is reduced, that is, $375,335,195$, and $163 \mathrm{~nm}$ at $-1,-2,-3$, and $-4 \mathrm{~mA} / \mathrm{cm}^{2}$, respectively. Moreover, the electrode prepared by pulse electrodeposition at $-1,-2,-3$, and $-4 \mathrm{~mA} / \mathrm{cm}^{2}$ displays size deviation of $\pm 30.82,59.91,18.82$, and 12.94, respectively. Especially, the $\mathrm{Cu}_{2} \mathrm{O}$ cube formed at the largest current density of $-4 \mathrm{~mA} / \mathrm{cm}^{2}$ has the smallest size and narrowest deviation of size. Fig. 3(e) and (f) show low and high resolution TEM images of the cube in the electrode electrodeposited at $-3 \mathrm{~mA} / \mathrm{cm}^{2}$. As indicated in the Fig. 3(e), the size of the cube is about $190 \mathrm{~nm}$, which is well consistent with SEM image in the electrode (Fig. 3(c)). However, the single-crystal texture for the (100) orientation of $\mathrm{Cu}_{2} \mathrm{O}$ with $\mathrm{d}$-spacing of $0.213 \mathrm{~nm}$, not $\mathrm{Cu}$ metallic phase. Also, it is evident that the inset of the Fig. 3(e) displays transmission electron diffraction (TED) pattern indicative of (100) orientation of $\mathrm{Cu}_{2} \mathrm{O}$. As a result, size-controlled $\mathrm{Cu}_{2} \mathrm{O}$ nanocubes could be synthesized by pulse electrodeposition as a function of applied current density. However, although the average size of the nanocubes is decreased, the number of the nanocubes is increased with increasing reduction current. There would be two mechanisms for the formation of the $\mathrm{Cu}_{2} \mathrm{O}$ nanocubes, i.e. the nucleation followed by the formation of new $\mathrm{Cu}_{2} \mathrm{O}$ grains and growth of existing nuclei. The deposition of $\mathrm{Cu}_{2} \mathrm{O}$ takes place only when the potential of the cathode is lower than the equilibrium electrode potential of the $\mathrm{Cu}_{2} \mathrm{O} / \mathrm{Cu}^{2+}$; hence, a certain magnitude of cathode potential is necessary. The relationship between the overpotential and nucleation rates has been given as follows:

$$
N=a \cdot \exp \left(-\frac{b}{\eta_{k}^{2}}\right)
$$

In the equation (4), the $\mathrm{N}$ is the nucleation rate; $\eta_{k}$ is the cathode overpotential; $a$ and $b$ are constants. ${ }^{23)}$ It can be seen that higher overpotential, which is higher reduction current, produces much higher nucleation rates and larger nucleation sites in the electro-crystallization process. Hence, this could lead to large number of deposited $\mathrm{Cu}_{2} \mathrm{O}$ nanocubes with small size. As shown in Fig. 3(f), the XRD peaks at around 36.4 and 42.2 assigned to (111) and (200) plane of the $\mathrm{Cu}_{2} \mathrm{O}$ crystal structure, respectively, were found. The relative intensity ratios of the (200) to (111) in the $\mathrm{Cu}_{2} \mathrm{O}$ nanocubes are relatively higher than that of the reference. According to Gibbs-Wulff's theorem, for the cubic crystallographic system, both the $\{111\}$ and $\{100\}$ faces can be easily maintained in the final appearance due to an equilibrium shape in order to minimize its interfacial free energy. ${ }^{24)}$ In addition, the morphology of the deposits shows a strong dependence on the reaction conditions, such as $\mathrm{pH}$ of the initial solution, temperature, reaction time and applied current density. Especially, it is likely that since the relative intensity ratios of the (200) to (111) in the $\mathrm{Cu}_{2} \mathrm{O}$ nanocubes are relatively higher than that of the reference, the $\mathrm{Cu}_{2} \mathrm{O}$ nano-cubes show 

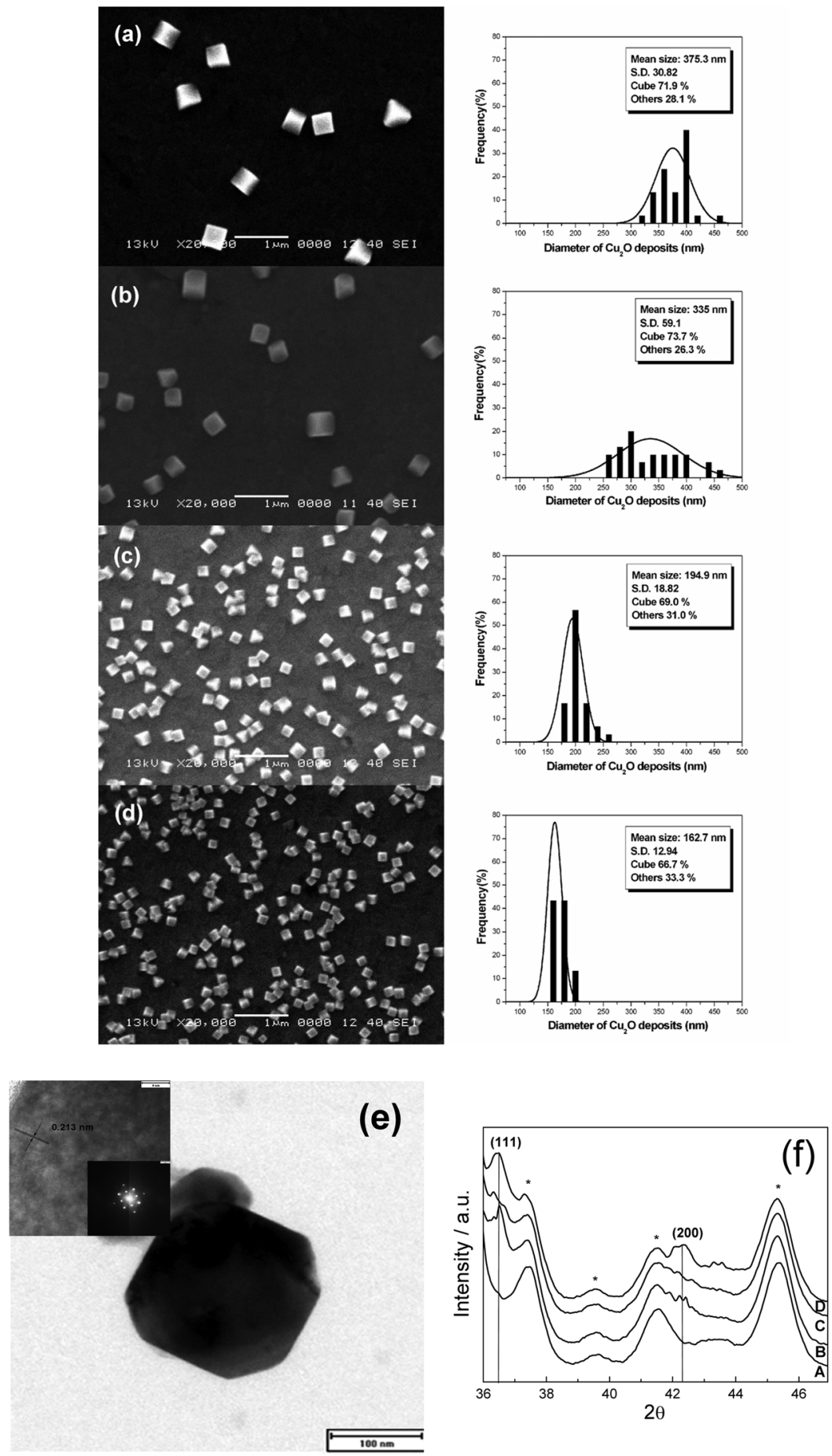

Fig. 3. SEM images and size histograms of the electrodes electrodeposited at (a) -1 , (b) -2 , (c) -3 and (d) $-4 \mathrm{~mA} / \mathrm{cm}^{2}$. (e) Low and high magnification TEM images of $\mathrm{Cu}_{2} \mathrm{O}$ nanocube electrodeposited at $-3 \mathrm{~mA} / \mathrm{cm}^{2}$. (The inset is TED pattern.) (f) XRD patterns of the electrodes electrodeposited at -1 (A), -2 (B), -3 (C) and -4 (D) $\mathrm{mA} / \mathrm{cm}^{2}$. The (*) mark represents the XRD patterns of ITO glass. 
growth along the $<100>$ direction in the condition, which is well consistent with TEM images.

\section{Conclusions}

We found that phase transition between oxidative and metallic state of $\mathrm{Cu}_{2} \mathrm{O}$ and $\mathrm{Cu}$ could be controlled as a function of an electrodeposition time under reduction current mode. Especially, the $\mathrm{Cu}_{2} \mathrm{O}$ nanocubes without any metallic agglomerate were obtained by means of electrodeposition during a short deposition time. Thus, the highly uniform size-controlled $\mathrm{Cu}_{2} \mathrm{O}$ nanocubes were fabricated using pulse electrodeposition method as a function of applied current density.

\section{Acknowledgment}

This work was supported by the National Research Foundation of Korea Grant funded by the Korean Government (NRF-2009-0065330), Human Resource Training Project for Strategic Technology, Manpower Development Program for Energy \& Resources supported by the Ministry of Knowledge and Economy.

\section{References}

1. G. P. Pollack and D. Trivich, 'Photoelectric properties of cuprous oxide' J. Appl. Phys., 46, 163 (1975).

2. R. Liu, E.A. Kulp, F. Oba, E.W. Bohannan, F. Ernst, and J.A. Switzer, 'Epitaxial Electrodeposition of High-Aspect-Ratio $\mathrm{Cu}_{2} \mathrm{O}$ (110) Nanostructures on $\operatorname{InP}(111)$ ' Chem. Mater., 17, 725 (2005)

3. A. O. Musa, T. Akomolafe, and M. J. Carter, 'Production of cuprous oxide, a solar cell material, by thermal oxidation and a study of its physical and electrical properties' Sol. Energ. Mat. Sol. C., 51, 305 (1998).

4. H. Xu, W. Wang, and W. Zhu, 'Shape Evolution and SizeControllable Synthesis of Cu2O Octahedra and Their Morphology-Dependent Photocatalytic Properties' J. Phys. Chem. B, 110, 13829 (2006).

5. S. T. Shishiyanu, T. S. Shisiyanu, and O. I. Lupan, 'Novel $\mathrm{NO}_{2}$ gas sensor based on cuprous oxide thin films' Sensors Actuators B, 113, 468 (2006).

6. P. Poizot, S. Laruelle, S. Grugeon, L. Dupont, and J. M. Tarascon, 'Nano-sized transition-metal oxides as negativeelectrode materials forlithium-ion batteries' Nature, 407, 496 (2000)

7. C. Q. Zhang, J.P. Tu, X. H. Huang, Y. F. Yuan, X. T. Chen, and F. Mao, 'Preparation and electrochemical performances of cubic shape $\mathrm{Cu}_{2} \mathrm{O}$ as anode material for lithium ion batteries' J. Alloy Comd., 441, 52 (2007).

8. P. E. de Jongh, D. Vanmaekelbergh, and J. J. Kelly,
'Photoelectrochemistry of Electrodeposited $\mathrm{Cu}_{2} \mathrm{O}$ ' J. Electrol hem. Soc., 147, 486 (2000).

9. A. P. Alivisatos, 'Semiconductor Clusters, Nanocrystals, and Quantum Dots' Science, 271, 933 (1996).

10. M. J. Siegfried and K.-S. Choi, 'Directing the Architecture of Cuprous Oxide Crystals during Electrochemical Growth' Angew. Chem. Int. Ed., 44, 3218 (2005).

11. A. L. Daltina, A. Addadb, and J. P. Choparta, 'Potentiostatic deposition and characterization of cuprous oxide films and nanowires' J. Cryst. Growth, 282, 414 (2005).

12. B. Balamurugan and B. R. Mehta, 'Optical and structural properties of nanocrystalline copper oxide thin films prepared by activated reactive evaporation' Thin Solid Films, 396, 90 (2001)

13. L. Gou and C. J. Murphy, 'Solution-Phase Synthesis of Cu2O Nanocubes' Nano Lett., 3, 231 (2003).

14. Z. Wu, M. Shao, W. Zhang, and Y. Ni, 'Large-scale synthesis of uniform $\mathrm{Cu} 2 \mathrm{O}$ stellar crystals via microwaveassisted route' J. Cryst. Growth, 260, 490 (2004).

15. Z. Z. Chen, E. W. Shi, Y.Q. Zheng, W. J. Li, B. Xiao, and J. Y. Zhuang, 'Growth of hex-pod-like $\mathrm{Cu}_{2} \mathrm{O}$ whisker under hydrothermal conditions' J. Cryst. Growth, 249, 294 (2003).

16. P. Taneja, R. Banerjee, and P. Ayyub, 'Structure and properties of nanocrystalline $\mathrm{Ag}$ and $\mathrm{Cu}_{2} \mathrm{O}$ synthesized by high pressure sputtering' Scr. Mater., 44, 1915 (2001).

17. P. R. Markworth, X. Liu, J.Y. Dai, W. Fan, T.J. Marks, and P. P. H. Chang, 'Coherent island formation of $\mathrm{Cu}_{2} \mathrm{O}$, films grown by chemical vapor deposition on $\mathrm{MgO}(110)$ ' J. Mater. Res., 16, 2408 (2001).

18. M. C. Tsai, T. K. Yeh, and C. H. Tsai, 'An improved electrodeposition technique for preparing platinum and platinum-ruthenium nanoparticles on carbon nanotubes directly grown on carbon cloth for methanol oxidation' Electrochem. Commun., 8, 1445 (2006).

19. X. Chen, N. Li, K. Eckhard, L. Stoica, W. Xia, J. Assmann, M. Muhler, and W. Schuhmann, Pulsed electrodeposition of Pt nanoclusters on carbon nanotubes modified carbon materials using diffusion restricting viscous electrolytes' Electrochem. Commun., 9, 1348 (2007).

20. M. Sun, G. Zangari, M. Shamsuzzoha, and R.M. Metzger, 'Electrodeposition of highly uniform magnetic nanoparticle arrays in ordered alumite' Appl. Phys. Lett., 78, 2964 (2001).

21. C. D. Wagner, W. M. Riggs, L. E. Davis, J. E. Moulder, and G. E. Muilenber, Handbook of X-ray Photoelectron Spectroscopy, Perkin Elmer Corporation Physical Electronics Division, USA, 1979.

22. A. O. Musa, T. Akomolafe, and M. J. Carter, 'Production of cuprous oxide, a solar cell material, by thermal oxidation and a study of its physical and electrical properties' Sol. Energy Mater. Sol. Cells, 51, 305 (1998).

23. T. Gao, G. Meng, Y. Wang, S. Sun, and L. Zhang, 'Electrochemical synthesis of copper nanowires' J. Phys. Condens. Matter, 14, 355 (2002).

24. J. Xu and D. Xue, 'Five branching growth patterns in the cubic crystal system: A direct observation of cuprous oxide microcrystals' Acta Mater, 55, 2397 (2007). 